\title{
Analisis faktor risiko terjadinya phlebitis di RSUD Puri Husada Tembilahan
}

\author{
Siti Rusnawati ${ }^{1 *}$, Hafni Bachtiar ${ }^{2}$, Deswita $^{3}$ \\ ${ }^{1}$ Mahasiswa S2 Keperawatan Universitas Andalas \\ ${ }^{2}$ Staf Pengajar Fakultas Kedokteran Universitas Andalas \\ ${ }^{3}$ Staf Pengajar Fakultas Keperawatan Universitas Andalas \\ *Correspondence email: sitiners@gmail.com
}

\begin{abstract}
Abstrak. Phlebitis merupakan salah satu indikator standar pelayanan minimal rumah sakit dengan dimensi mutu keselamatan pasien. Faktor risiko terjadinya phlebitis diantaranya penyakit, ukuran kateter intravena, jarak tempat insersi dengan persendian, jenis cairan, tehnik desinfeksi, tehnik dressing dan lama infus terpasang. Penelitian ini bertujuan untuk menganalisis faktor risiko terjadinya phlebitis. Metode yang digunakan adalah analitik crossectional observasional yang dilakukan di RSUD Puri Husada Tembilahan terhadap 97 pasien. Hasil penelitian menunjukkan bahwa faktor yang berhubungan dengan terjadinya phlebitis adalah jarak tempat insersi dengan persendian, jenis cairan, tehnik desinfeksi, tehnik dressing, dan lama infus terpasang, sedangkan faktor penyakit dan ukuran kateter intravena tidak berhubungan dengan terjadinya phlebitis. Faktor yang paling dominan berhubungan dengan phlebitis adalah tehnik desinfeksi $(\mathrm{OR}=4,567)$. Hasil penelitian ini dapat menjadi informasi bagi perawat dalam pencegahan terjadinya phlebitis dengan melakukan desinfeksi dan dressing dengan tehnik steril pada saat pemasangan infus, memantau tetesan infus sesuai dengan terapi, melakukan insersi dengan jarak $>3,5 \mathrm{~cm}$ dari persendian, dan mengganti tempat insersi pada pasien yang terpasang infus $>72$ jam.
\end{abstract}

Kata Kunci: Phlebitis; jarak tempat insersi; cairan; desinfeksi; dressing; lama infus terpasang

Abstract. Phlebitis is one of the standard indicators of hospital's minimum service with the dimension of patient safety quality. Risk factors for phlebitis include disease, intravenous catheter size, distance insertion place with joints, type of fluid, technique disinfection, dressing techniques and long infusion attached. The research aims to analyse the risk factors of phlebitis. The methods used were observational crossectional analytic conducted in Puri Husada Tembilahan HOSPITAL against 97 patients. The results showed that the factors related to the occurrence of phlebitis is the distance of insertion place with the joints, types of liquids, techniques of disinfection, technique dressings, and prolonged infusion is attached, while the disease factors and the size of the catheter intravenously unrelated to the occurrence of phlebitis. The most dominant factor is related to Phlebitis is disinfection technique $(O R=4.567)$. The results of this research can be information for nurses in the prevention of phlebitis by conducting disinfection and dressing with sterile technique during the installation of infusion, monitor drip infusion according to therapy, insertion with Distance $>3.5 \mathrm{~cm}$ from the joints, and replacing the place of insertion in the patient's attached infusion > 72 hours.

Keyword: Phlebitis; distance of insertion; liquid; disinfection; dressing; duration of infusion installed

\section{PENDAHULUAN}

Terapi infus merupakan salah satu tindakan yang paling sering digunakan dalam pelayanan kesehatan di seluruh dunia yang bertujuan untuk pemenuhan kebutuhan cairan, pengobatan, transfusi darah dan pengambilan sampel darah. Sekitar 50\% pasien yang masuk rumah sakit mendapat terapi melalui infus (David, 2005; Singh et al., 2008). Menurut Scales (2009) peran perawat dalam terapi infus bukan hanya untuk pemberian agen pengobatan, tetapi lebih luas meliputi pemasangan alat akses IV, perawatan, monitoring, dan yang lebih penting adalah pencegahan infeksi.

Komplikasi yang sering terjadi akibat terapi infus adalah phlebitis. Phlebitis merupakan reaksi inflamasi yang terjadi pada pembuluh darah vena yang ditandai dengan nyeri, kemerahan, bengkak, panas, indurasi (pengerasan) pada daerah insersi, dan pengerasan pada sepanjang pembuluh darah vena (Alexander et al., (2011). Menurut Gallant dan Schulz (2006) dalam Dougherty dan Lamb (2008) phlebitis terjadi antara 25 $70 \%$ dari seluruh pasien yang terpasang infus. Perawat harus melakukan pemeriksaan tempat insersi secara rutin terhadap tanda-tanda phlebitis dan mengkaji faktor risiko terjadinya phlebitis. Menurut Ingram dan Lavery (2005); Hankins et al., (2001); Ignatavicius dan Workman (2010); Pery dan Potter, 2009), phlebitis dapat disebabkan oleh beberapa faktor risiko diantaranya penyakit, ukuran kateter intravena, lokasi tempat nsersi, jenis cairan, kurangnya tehnik desinfeksi pada saat pemasangan infus, balutan (dressing) yang tidak steril pada tempat insersi dan waktu pemasangan kateter intravena yang telalu lama.

\section{METODE}

Penelitian ini menggunakan desain analitik crossectional yang bertujuan menganalisis hubungan penyakit, ukuran kateter intravena, jarak tempat insersi, jenis cairan, tehnik desinfeksi, tehnik dressing dan lama infus terpasang dengan terjadinya phlebitis. 


\section{HASIL DAN PEMBAHASAN}

Hasil

Penelitian ini dilakukan di RSUD Puri Husada Tembilahan dengan sampel sebanyak 97 orang. Hasil penelitian menunjukkan bahwa terdapat 44 orang $(45,4 \%)$ mengalami phlebitis, sebagian besar berjenis kelamin perempuan yaitu 58 pasien $(59,8 \%)$ dan umur rata-rata 36,03 $\pm 9,904$ tahun.

Penyakit yang dialami pasien lebih dari separuh tidak risiko yaitu 63 orang $(64,9 \%)$, lebih dari separuh pasien diberikan ukuran kateter intravena $18 \mathrm{G}$ yaitu 44 orang $(45,4 \%)$. Jarak rata-rata tempat insersi dengan persendian 3,224 $\pm 1,1084 \mathrm{~cm}$, lebih dari separuh pasien diberikan cairan isotonis yaitu 64 orang (66\%), lebih dari separuh pasien dilakukan desinfeksi dengan tehnik steril pada saat pemasangan infus yaitu 57 orang $(58,8 \%)$, lebih dari separuh pasien dilakukan dressing dengan tehnik tidak steril pada saat pemasangan infus yaitu 53 orang $(54,6 \%)$ dan rata-rata lama infus terpasang $75,37 \pm 15,601$ jam.

Tabel 1. Hubungan Penyakit, Ukuran Kateter Intravena, Jarak Tempat Insersi, Jenis Cairan, Tehnik Desinfeksi, Tehnik Dressing Dan Lamaa Pemasangan Infus Dengan Terjadinya Phlebitis di RSUD Puri Husada Tembilahan

\begin{tabular}{|c|c|c|c|c|c|}
\hline \multirow{2}{*}{ Variabel } & \multirow{2}{*}{ Total } & \multicolumn{2}{|c|}{ Phlebitis } & \multirow{2}{*}{ OR } & \multirow{2}{*}{$p$} \\
\hline & & Tidak & $\mathrm{Ya}$ & & \\
\hline \multicolumn{6}{|l|}{ Phlebitis, f(\%) } \\
\hline Tidak & $53(54,6 \%)$ & - & - & - & - \\
\hline $\mathrm{Ya}$ & $44(45,4 \%)$ & - & - & - & - \\
\hline \multicolumn{6}{|l|}{ Penyakit, f (\%) } \\
\hline Tidak Risiko & $63(64,9)$ & $39(61,9)$ & $24(38,1)$ & 2,321 & 0,081 \\
\hline Risiko & $34(35,1)$ & $14(41,2)$ & $20(58,8)$ & $(0,99-5,44)$ & \\
\hline \multicolumn{6}{|l|}{ Ukuran Kateter IV, f (\%) } \\
\hline 20 & $53(54,6)$ & $27(50,9)$ & $26(49,1)$ & 0,179 & 0,550 \\
\hline 18 & $44(45,4)$ & $26(59,1$ & $18(40,9)$ & $(0,3-1,6)$ & \\
\hline $\begin{array}{l}\text { Tempat Insersi } \\
\text { Rata-rata } \pm \text { SD) }\end{array}$ & $3,224 \pm 1,1084$ & $3,598 \pm 0,7946$ & $2,773 \pm 1,246$ & (2) 5 , & 0,000 \\
\hline \multicolumn{6}{|l|}{ Jenis Cairan, $\mathrm{f}(\%)$} \\
\hline Isotonis & $65(67)$ & $41(63,1)$ & $24(36,9)$ & 2,847 & \multirow{2}{*}{0,031} \\
\hline Isotoni + Hipertonis & $32(33)$ & $12(37,5)$ & $20(62,6)$ & $(1,2-6,8)$ & \\
\hline \multicolumn{6}{|l|}{ Tehnik Desinfeksi, f (\%) } \\
\hline Steril & $57(58,8)$ & $38(66,7)$ & $19(33,3)$ & 3,333 & \multirow[t]{2}{*}{0,008} \\
\hline Tidak Steril & $40(41,2)$ & $15(37,5)$ & $25(62,5)$ & $(1,4-7,7)$ & \\
\hline \multicolumn{6}{|l|}{ Tehnik Dressing, f(\%) } \\
\hline Steril & $43(44,3)$ & $31(72,1)$ & $12(27,9)$ & 3,758 & \multirow[t]{2}{*}{0,004} \\
\hline Tidak Steril & $54(55,7)$ & $22(40,7)$ & $32(59,3)$ & $(1,6-8,9)$ & \\
\hline \multicolumn{6}{|l|}{ Lama Pemasangan Infus } \\
\hline$\leq 72$ jam & $43(44,3 \%)$ & $29(67,4 \%)$ & $14(32,6 \%)$ & 2,589 & \multirow{2}{*}{0,04} \\
\hline$>72$ jam & $54(55,7 \%)$ & $24(44,4 \%)$ & $30(55,6 \%)$ & $(1,1-5,96)$ & \\
\hline
\end{tabular}

Berdasarkan analisis statistik diperoleh hasil bahwa persentase terjadinya phlebitis lebih tinggi pada pasien dengan penyakit risiko dibandingkan dengan pasien dengan penyakit tidak risiko $(58,8: 38,1)$ dengan $\mathrm{p}>0,05$. Persentase terjadinya phlebitis pada pasien dengan ukuran kateter intravena $20 \mathrm{G}$ lebih tinggi dibandingkan pasien dengan ukuran kateter intravena 20 $\mathrm{G}(49,1: 40,9), \mathrm{p}>0,05$.

Rata-rata jarak tempat insersi dengan persendian pada pasien yang mengalami phlebitis lebih dekat dibandingkan yang tidak phlebitis $(3,588 \pm 0,7946$ : $2,773 \pm 1,246)$ dengan $\mathrm{p}<0,000$. Persentase terjadinya phlebitis pada pasien yang diberikan cairan isotonis + hipertonis lebih tinggi dibandingkan pasien yang hanya diberikan cairan isotoni $(63,6: 35,9), \mathrm{p}<0,005$ dengan OR 3,120. Persentase terjadinya phlebitis pada pasien yang dilakukan desinfeksi dengan tehnik tidak steril lebih tinggi dibandingkan dengan tehnik steril (62,5 $: 33,3), \mathrm{p}<0,000$ dengan OR : 3,333. Persentase terjadinya phlebitis pada pasien yang dilakukan dressing dengan tehnik tidak steril lebih tinggi dibandingkan dengan tehnik steril $(58,5: 29,5), \mathrm{p}<0,000$ dengan OR : 3,360 . Rata lama pemasangan infus pada pasien tidak phlebitis lebih lama dibandingkan pasien phlebitis $(80,68 \pm 11,312: 68,96 \pm 17,665)$.

Tabel 2. Faktor Yang Paling Dominan Berhubungan Dengan Terjadinya Phlebitis di RSUD Puri Husada Tembilahan

\begin{tabular}{clc}
\hline No & Variabel & OR \\
\hline 1 & Jarak tempat insersi & 0,449 \\
2 & Lama infus terpasang & 2,679 \\
3 & Tehnik dressing & 3,144 \\
4 & Jenis cairan & 4,495 \\
5 & Tehnik desinfeksi* & 4,567 \\
\hline
\end{tabular}

Berdasarkan analisis multivariat menggunakan regresi logistik diperoleh hasil faktor yang paling dominan berhubungan dengan terjadinya phlebitis adalah tehnik desinfeksi pada saat pemasangan infus (OR: 4,567). 


\section{Pembahasan}

Phlebitis merupakan salah satu komplikasi pemasangan infus yang dapat meningkatkan lama hari rawat di rumah sakit, menambah lama terapi dan meningkatkan tanggung jawab perawat serta dapat meningkatkan risiko masalah kesehatan lain (Alexander et al., 2011). Hasil penelitian menunjukkan bahwa tidak terdapat hubungan antara penyakit dengan risiko terjadinya phlebitis, namun kecenderungan terjadinya phlebitis pada pasien yang mengalami penyakit risiko lebih tinggi. Penyakit risiko yang dimaksud dalam penelitian ini adalah penyakit yang meningkatkan risiko terjadinya phlebitis yaitu diabetes mellitus, HIV, kanker, gagal ginjal, luka bakar, penyakit jantung, pengakit ginjal dan anemia. Penelitian ini tidak sesuai dengan yang dilakukan Nassaji-Zavareh dan Ghorbani (2007) yang diperoleh hasil bahwa terdapat hubungan antara penyakit infeksi, diabetes mellitus dan luka bakar dengan terjadinya phlebitis.

Penelitian menunjukkan bahwa tidak terdapat hubungan antara ukuran kateter intravena dengan risiko terjadinya phlebitis. Hal menunjukkan bahwa phlebitis tidak hanya dipengauhi oleh ukuran kateter intravena, namun dapat dipengaruhi oleh faktor yang lain seperti jenis cairan, penyakit, tempat pemasangan infus, lama pemasangan infus dan tehnik steril pada saat pemasangan infus. Penelitian ini sesuai dengan penelitian yang dilakkan Neopane (2013) bahwa tidak terdapat hubungan antara ukuran kateter intravena dengan terjadinya phlebitis.

Jarak tempat insersi yang terlalu dekat dengan persendian dapat mengakibatkan pergerakan kateter intravena di dalam pembuluh darah yang dapat meningkatkan risiko terjadinya phlebitis. Hasil penelitian menunjukkan bahwa terdapat hubungan antara jarak tempat insersi dengan risiko terjadinya phlebitis. Pasien yang tidak phlebitis memiliki jarak tempat insersi lebih jauh dibandingkan dengan pasien yang phlebitis (3,588 $\pm 0,7946$ : $2,773 \pm 1,246 \mathrm{~cm})$. Penelitian ini sesuai dengan penelitian yang dilakukan Gayatri dan Handiyani (2008) yang diperoleh hasil jarak tempat insersi dari persendian $3-7 \mathrm{~cm}$ akan menurunkan risiko terjadinya phlebitis.

Jenis cairan memiliki pengaruh terhadap tunika intima darah, dimana dinding tunika intima akan mengalami trauma pada saat pemberian cairan hipertonis terlebih jika tetesan cepat. Hasil penelitian menunjukkan terdapat hubungan antara pemberian cairan isotonis + hipertonis dengan risiko terjadinya phlebitis. Penelitian ini sesuai dengan penelitian yang dilakukan oleh Uslusoy dan Mate (2008); Sriupayo et al., (2014) bahwa terdapat hubungan yang signifikan antara jenis cairan dengan terjadinya phlebitis dimana pasien yang diberikan cairan hipertonis memiliki risiko lebih tinggi untuk terjadinya phlebitis dibandingkan pasien yang hanya diberikan cairan isotonis.
Hasil penelitian menunjukkan terdapat hubungan tehnik desinfeksi dan tehnik dressing dengan terjadinya phlebitis. Pasien yang dilakukan tehnik desinfeksi tidak steril pada saat pemasangan infus memiliki risiko 3,333 kali terjadinya phlebitis dibandingkan dengan pasien yang dilakukan desinfeksi dengan tehnik steril. Pasien yang dilakuka tehnik dressing tidak steril pada saat pemasangan infus memiliki risiko 3,360 kali terjadinya phlebitis dibandingkan dengan pasien yang dilakukan dressing dengan tehnik tidak steril. Hal ini sesuai dengan pernyataan Curverwell (2013) bahwa tehnik aseptik (desinfeksi) yang kurang pada saat pemasangan infus dapat mengakibatkan kontaminasi melalui tangan pada area insersi dan balutan (dressing) yang tidak steril pada tempat insersi dapat mengakibatkan kontaminasi pada area insersi.

Lama pemasangan infus dalam terapi intravena akan mempengaruhi terjadinya phlebitis. Hasil penelitian menujukkan bahwa lama infus terpasang berhubungan dengan terjadinya phlebitis. Pasien yang terpasang infus $>72$ jam memiliki risiko 2,589 kali untuk terjadinya phlebitis dibanding pasien yang terpasang infus $\leq 72$ jam. Faktor yang paling dominan berhungan dengan terjadinya phlebitis adalah tehnik desinfeksi pada saat pemasangan infus. Hal ini sesuai dengan pendapat Alexander et al., (2011) bahwa kurangnya tehnik aseptik mengakibatkan kontaminasi melalui area insersi sehingga dapat terjadi phlebitis.

\section{SIMPULAN}

Berdasarkan hasil penelitian dapat disimpulkan bahwa terdapat hubungan antara jarak tempat insersi dengan persendian, jenis cairan, tehnik desinfeksi, tehnik dressing dan lama infus terpasang dengan terjadinya phlebitis. Tidak terdapat hubungan antara penyakit dan ukuran kateter intravena dengan terjadinya phlebitis. Faktor yang paling dominan berhubungan dengan terjadinya phlebitis adalah tehnik desinfeksi pada saat pemasangan infus.

\section{Saran}

Disarankan kepada perawat/bidan untuk melakukan desinfeksi dan dressing dengan tehnik steril pada saat pemasangan infus, melakukan insersi dengan jarak $>3,5 \mathrm{~cm}$ dari persendian, melakukan monitor tetesan infus seseuai dengan terapi, dan melakukan penggantian tempat insersi pada pasien yang terpasang infus $\leq 72$ jam.

\section{DAFTAR PUSTAKA}

Alexander, M, Corrigan, A, Gorski, L, Hankins, J., \& Perucca, R. (2011). Infusion nursing society, infusion nursing: an evidence based approach. Third Edition. St. Louis: Sauders Elsevier

Culverwell, E. (2013). Pheriperal intravenous cannulation self learning package. Canterbury District Health Board 
Dougherty, L. \& Lamb, J. (2008). Intravenous therapy in nursing practice. 2nd Edition. Blackwell Publishing

David, H. (2005). Infections due to percutaneous intravascular devices. in: principles and practices of infectious diseases. 6th ed. Philadelphia: Churchill Livingstone

Gayatri, D., \& Handiyani, H. (2008). Hubungan jarak pemasangan terapi intravena dari persendian terhadap waktu terjadinya flebitis. Jurnal Keperawatan Indonesia, 11(1), 1-5

Hankins, J., Lonsway, R.A.W., Hedrick, C., Perdue, M.B. (2001). The infusion nurse society: infusion therapy in clinical practice. $2^{\text {ed }}$. Philadelphia: W.B. Saunders Company

Ingram, P., \& Lavery, I. (2005). Peripheral intravenous theraphy: Key Risk And Implications For Practice.Nursing Standard.

Ignatavicius, D.D., \& Workman, M.L. (2010). Medical surgical nursing. St. Louis Missouri

Nassaji-Zavareh M., \& Ghorbani R. (2007). Peripheral intravenous catheter - related phlebitis and related risk factors. Singapore Medical Journal. 48(8), 733-736

Neopane, A. (2013. Peripheral venous trhombophlebitis risk and the role of hand washing. Nepal Journal Of Medical Sciences. Volume 02 No. 01 Jan - Jun 2013

Perry, A.G., \& Potter, P.A. (2009). Fundamental of nursing. Seventh Edition. St. Louis Massouri: Mosby Inc

Singh, R., Bhandary, S., \& Pun, K.D. (2008). Peripheral intravenous catheter related phlebitis and its contributing factors among adult population at $\mathrm{KU}$ Teaching Hospital. Kathmandu University Medical Journal. Vol. 6, No. 4, Issue 24, 443-447

Scales, K. (2009). Intravenous therapy: the legal and professional aspects of practice. Nursing Standard. 23(33), 51-57

Sriupayo, A., Inta, N., Boonkongrat, S., Kaphan, K., Uttama, J., Budssabongphiwa, S., et al. (2014). Effectiveness of peripheral vascular catheter care budle in the pediatric nursing service, Chiang May University Hospital, Thailand. Chiang Mai Medical Journal. 53(2)

Uslusoy, E., \& Mete, S. (2008). Predisposing factors to phlebitis in patiens with peripheral intravenous catheters: A descriptive study. Journal of The American Academy Of Nurse Practituioners. April 2008 pg. 172 